\title{
Semantic Analysis of the Entrepreneurship Environment in Madhya Pradesh: Building an Entrepreneurship Ecosystem
}

\author{
Aenita Kunari \\ Assistant Professor, Department of Commerce, Dr. Harisingh Gour Vishwavidyalaya Sagar, Madhya Pradesh, India
}

\begin{abstract}
India ranks third in the global startup ecosystem in the world incubating more than 50, 000 startups and witnessing $15 \%$ YoY growth per year. Being a center of innovation and skilled labor, Indian startups have attracted investments from all over the world. This paper aims at exploring the trends that are driving the growth in the Indian startup ecosystem. The state of Madhya Pradesh, often referred to as the heart of India, has, attracted investments in a diverse mix of sectors ranging from heavy engineering, information technology, electronics system design and manufacturing (ESDM), Telecommunications and automobiles. As a result, one of the interesting aspects about the state is the abundance of skilled technical workforce, thereby providing a tailor - made platform to promote startups in the state. In order to ignite the spirit of entrepreneurship and innovation for people in the state and converting ideas into potential businesses, the state government, in 2016, outlined a startup policy to provide an enabling environment to achieve this objective. Like many emerging ecosystems, Madhya Pradesh also has a culture of copying business models of big successes and applying the model for the smaller markets in the state. This shows that the state has an aspiration for entrepreneurship but innovation is still at a nascent stage. But this does not mean there is no glimmer of hope, some mavericks have indeed broken the mould to build out - of - the - box ideas into businesses.
\end{abstract}

Keywords: Sustainable development; Entrepreneurship; Innovative startups; India; Small business

JEL Classification Numbers: E22, E24, E32, E44.

\section{Introduction}

India has an estimated 26,000 startups, making it the third largest startup ecosystem in the world, recording consolidated inflows of over $\$ 36$ billion in the past 3 years with 26 "unicorns"-startups valued over \$1billion. The Indian startup ecosystem has expanded quite rapidly mainly through private investments including seed, angel, venture capital, and private equity funds, with technical support from incubators, accelerators, and the government. The government, for its part, is creating an enabling environment through its flagship Startup India initiative, which came into force in 2016. With India pushing towards a knowledge based and digital economy, the government is attempting to deploy ICT infrastructure and provide policy support for enhanced e -governance, investments, and technology innovation through research and higher education to support entrepreneurship and spur economic growth. Data suggest that the expansion in the startup ecosystem has largely been clustered in the large (Tier1) cities and states with financial depth and especially in IT- enabled sectors including ecommerce, transport, and finance. Small businesses beyond the metros are not fully aware of, or integrated into, programs that provide startups with various government incentives and tax breaks. Madhya Pradesh is also home to some of the most renowned educational institutes of India such as the Indian Institute of Management (IIM), Indore, the Indian Institute of Technology (IIT) Indore, All India Institute of Medical Science (AIIMS), National Institute of Fashion Technology (NIFT), Bhopal, Polytechnics and several Industrial Training Institutes (ITIs). Availability of skilled man power along with proportional number of training institutes makes the state an ideal destination for startups. The state has evolved its policies to offer a startup friendly ecosystem with a clear focus on incubation, funding and individual startups. The policy offers benefits and incentives across various areas of intervention to startups. Madhya Pradesh Industrial Development Corporation (MPIDC) has emerged as the leading investment promotion agency worldwide. In the field of investment promotion, the state scored $97 \%$. In parameters comprising inviting investors, taking investment to Madhya Pradesh, providing investors with facilities after setting up companies, building infrastructure and website, the state scored $100 \%$. Madhya Pradesh is the second largest state in India and is among the fastest growing ones with significant investments and economic growth in the past few years. The State of Madhya Pradesh has developed a robust infrastructure along with conducive policy environment and industrial growth centred which has boosted the growth of industrialisation. Realising the high potential in the manufacturing industry, this State has positioned itself as a favourable destination for high tech industries with heavy Engineering, IT, Telecommunications, ESDM, Automobiles, Textiles, Cement, Pharmaceuticals, Agro and Food Processing based industries by establishing a dedicated Industrial Cluster in various places across the State. This has increased the growth of industries and has, therefore, resulted in the higher demand for Incubation, Plug and Play facilities for upcoming entrepreneurs in the State. This article talks about the various features of the Madhya Pradesh Incubation and Startup Policy.

\section{Objective of Study}

This study has contributed toward structuring and documenting the growth driving trends and it will help the budding entrepreneurs to get familiar with the contemporary trends, pros and cons associated with it and the ways to leverage these trends to build a successful startup. The study 
also shows enhancement of the business ecosystem for start - ups.

The Inflection Point for Indian Startups: The period 2014-15 is considered an inflection point for the Indian startup ecosystem with the emergence of six "unicorns" in those 2 years. Since then, the Indian startup ecosystem has evolved steadily owing to several underlying factors, including:

- Demographic dividend: 600 million citizens are still under the age of 25, with rising internet, smartphone, and financial penetration

- Market size: growing middle class with increasing disposable income and social media adoption, changing consumer demographics that were previously inaccessible, with mobile and data tariffs among the lowest in the world

- Number of startups: incorporated and increasing number of active domestic and foreign angels/VC funders

- Political will: improvement in ease of doing business and conducive innovation environment through adoption of digital technologies and government initiatives like Startup India and Digital India and establishing regulatory infrastructure.

- Spillover effects from large, listed (and unlisted) technology firms: Many investors and a growing pool of experienced serial entrepreneurs.

- Higher education: India has a huge pool of engineering and technical graduates (though many need training before they can be employed) At first glance, gas pricing in India appears notoriously complicated, as there are a variety of different prices at the wellhead. In a nutshell: the price of domestic gas to producers is set according to the terms of the fiscal regime that governs a producing field.
- Emergence of startup hubs: agglomeration effect in Tier 1 cities has created larger clusters of startups, investors, and supporting infrastructure.

- Industry - academic - government linkages: growth in the number of university and industry - led incubators and accelerators, and setting up of government patent hubs One of the major shifts in making digital services more accessible to the masses was spurred by the telecom industry shake - up, driven largely by a new entrant, Reliance Jio's price war over data in 2016. This near commoditization of the internet gave Indians the world's cheapest data plans and opened up an entirely new user base.

\section{India's Startup Opportunity and Funding Opportunities}

\subsection{Recent Trends in Investment in Indian Startups and Data Availability}

Between 2011 and 2015, investment values increased at a compound annual growth rate (CAGR) of over $75 \%$ and the number of deals at a CAGR of over $80 \%$. Since then, VC investments have increased rapidly according to various estimates and peaked in 2019. under the Nomination Regime (covering the period from Independence to the early 1990s, whilst exploration and production turned into carried out completely by means of the NOCs) costs have been constant via the government below its Administered rate Mechanism (APM) on a 'price - plus' basis - or expenses plus a regulated price - of - return. There have been a few exceptions to this - gas sold to India's northeastern states, historically taken into consideration to be underdeveloped, turned into at a $40 \%$ cut price on the APM price, with the distinction paid as a subsidy to the NOCs. Similarly, the authorities authorized fuel from sure certain fields operated

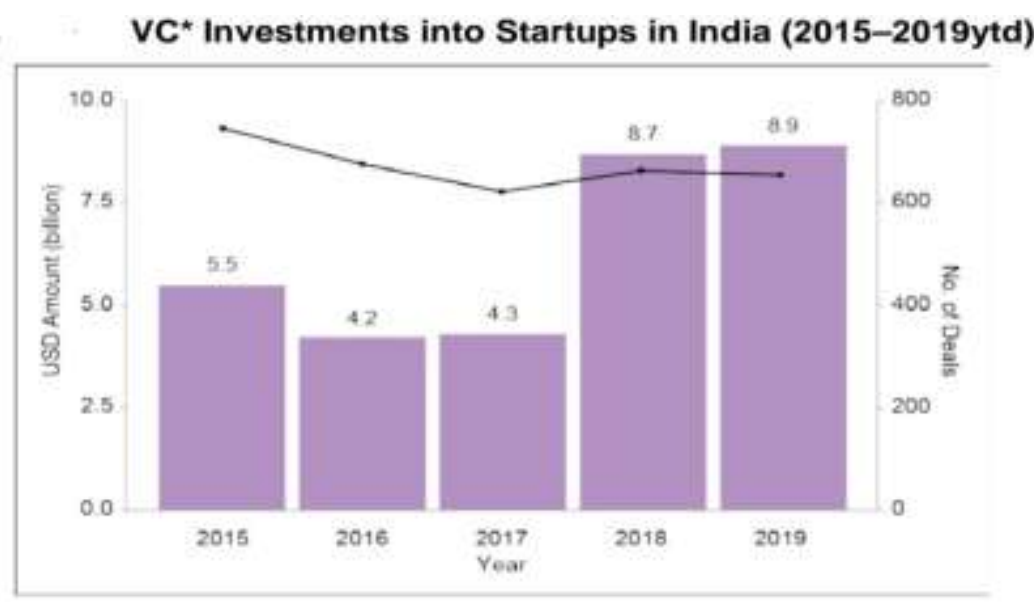

A challenge for obtaining data on startup finance is that they are mostly in the private realm where companies charge a subscription fee for accessing investment data and corporate financials (e. g., Venture Intelligence, Tracxn, etc.). For this paper, we have used two main sources for tracking startup funding:

1) Proprietary data from Venture Intelligence (VI): a private firm launched in 2002 and considered a leading source of information and analysis on private company financials, transactions (private equity, venture capital, and M\&A), and their valuations in India. VI provided only anonymized startup investment data that provided general trends, without any detailed/company - level data, as that would incur a fee.

2) Open - source data web - scraped from Trak. in: a business news and opinion site that also tracks investments in startups but with open - access data that is sourced publicly. This data was useful because it tracks detailed information but lacks clear definitions and classification. It required data - cleaning but it was 
helpful for our empirical analysis, where, for example, we needed granular company - level investment data across various states. The charts below roughly show the difference and details in the data in terms of the value of startup investments, which can be compared with the earlier chart from VI (Figure 2).

\section{Yearly and Monthly Investment data into Startups in India from trakin.com, 2015-2019}

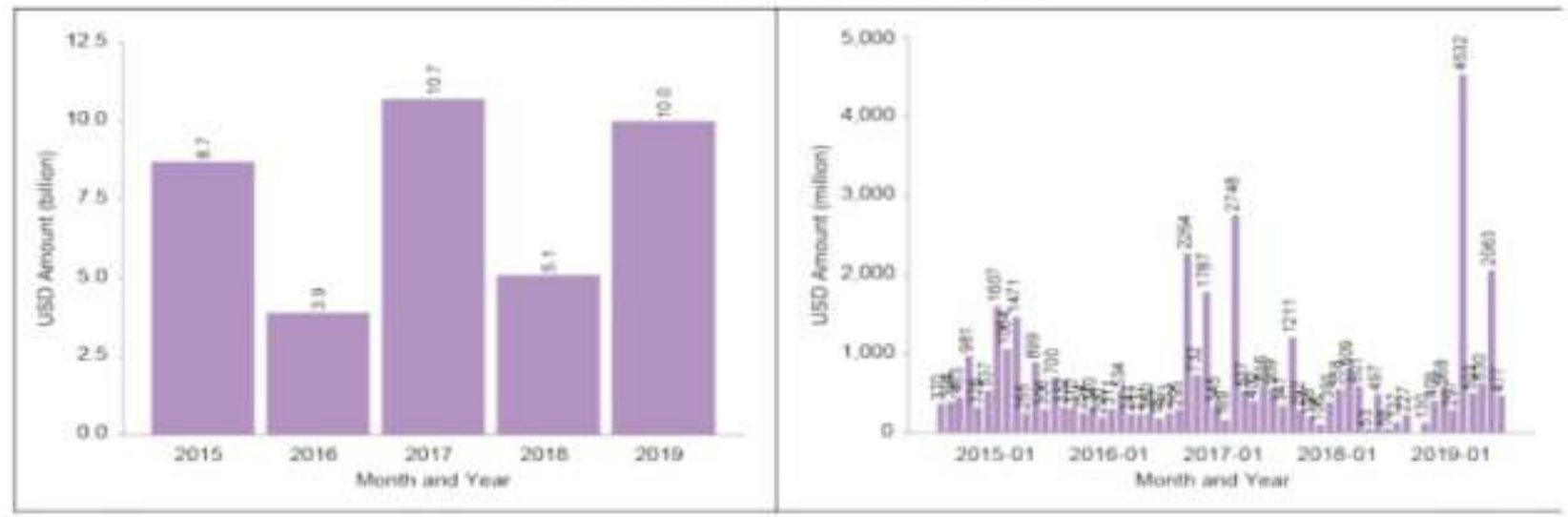

Economic Outlook -GSDP:
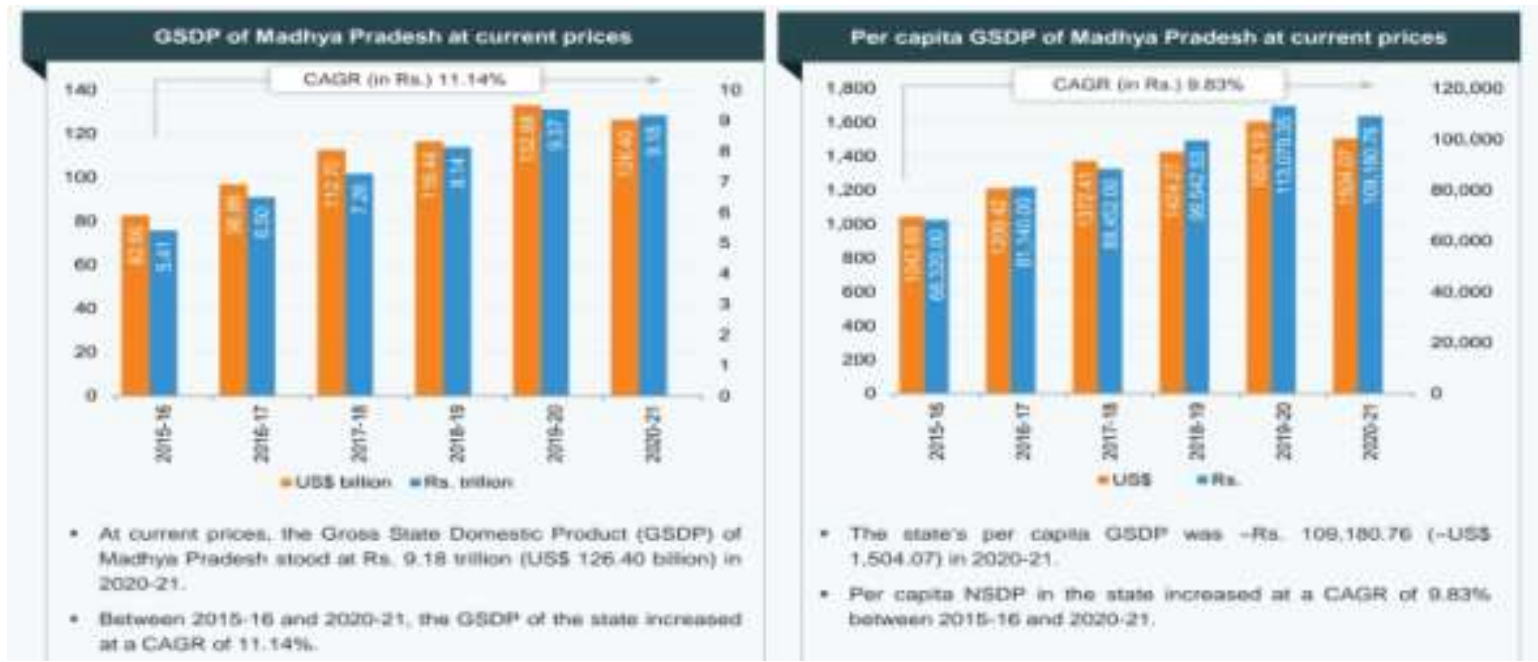

Economic Outlook-NSDP:

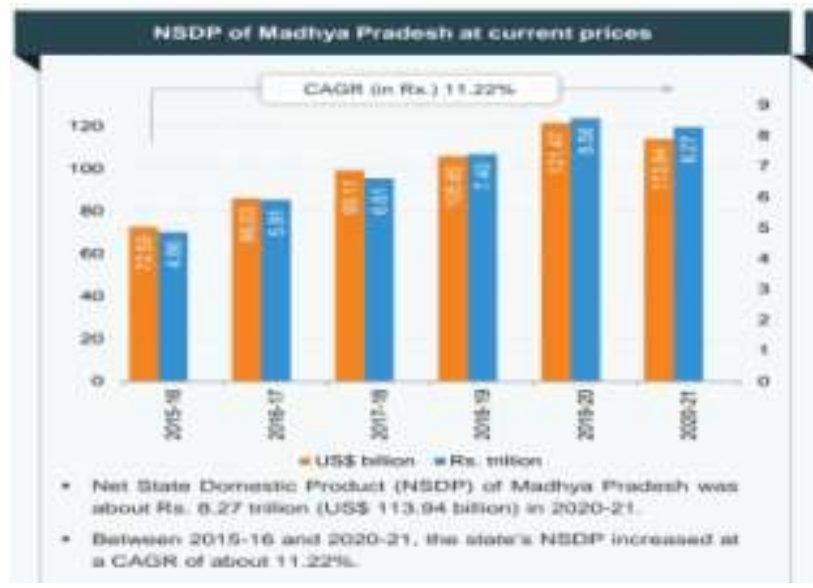

Per Capita NabP of Madhya Pradeah at current prices

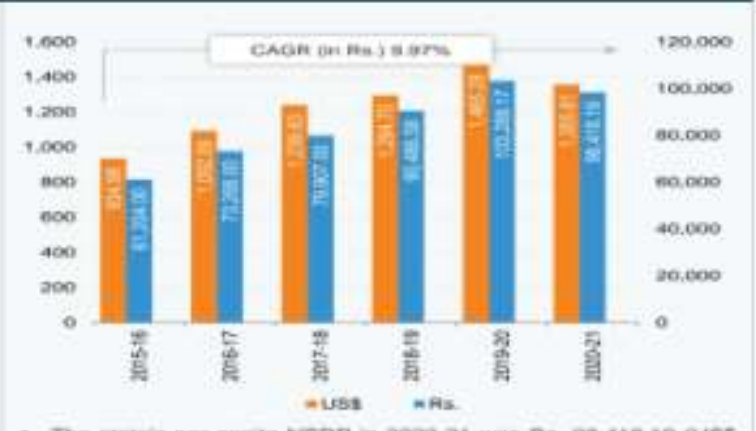

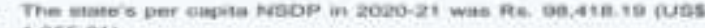
1,ass nt1)

Pat capina Nabe of the utas. between zo15-15 and zopo-2t

Economic Outlook -Percentage distribution of GSVA:

1) In 2020 - 21, the primary sector contributed $46.98 \%$ to the state's GSVA at current prices, followed by the tertiary sector $(33.55 \%)$ and secondary sector (19.47\%).

2) At a CAGR of $16.49 \%$, the primary sector witnessed the fastest growth among the three sectors between FY12 and FY21.

3) The tertiary sector expanded at a CAGR of $10.44 \%$ between FY12 and FY21. Growth was driven by trade, 
hotels, real estate, finance, insurance, transport, communications and other services.

4) The secondary sector expanded at a CAGR of $8.28 \%$ between FY12 and FY21, driven by the manufacturing, electricity, gas \& water supply and construction sectors.

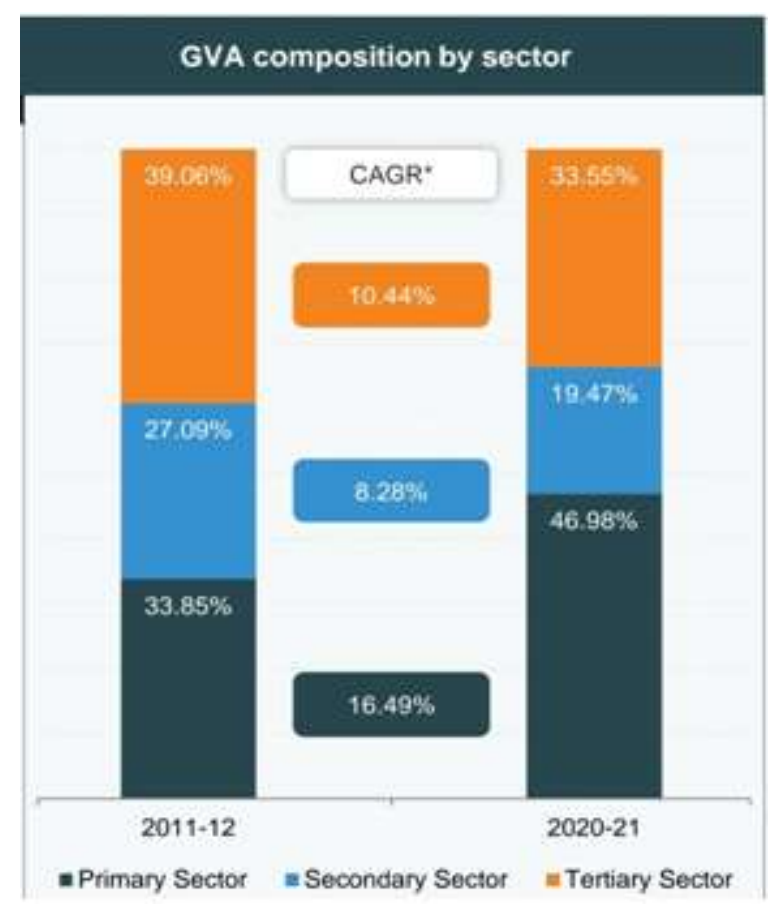

Economic Outlook -FDI inflow \& investments:

1) According to the Department for Promotion of Industry and Internal Trade (DPIIT), cumulative FDI inflow in Madhya Pradesh was valued at US\$ 282.29 million between October 2019 and March 2021.

2) The state will be holding the sixth edition of its Global Investors Summit in October 2019. At the previous edition, the state witnessed expression of interest's worth Rs.5, 62, 887 crore (US\$ 83.75 billion).

3) 2.93 investment intentions worth US\$ 4.42 billion were filed in the state during 2020.

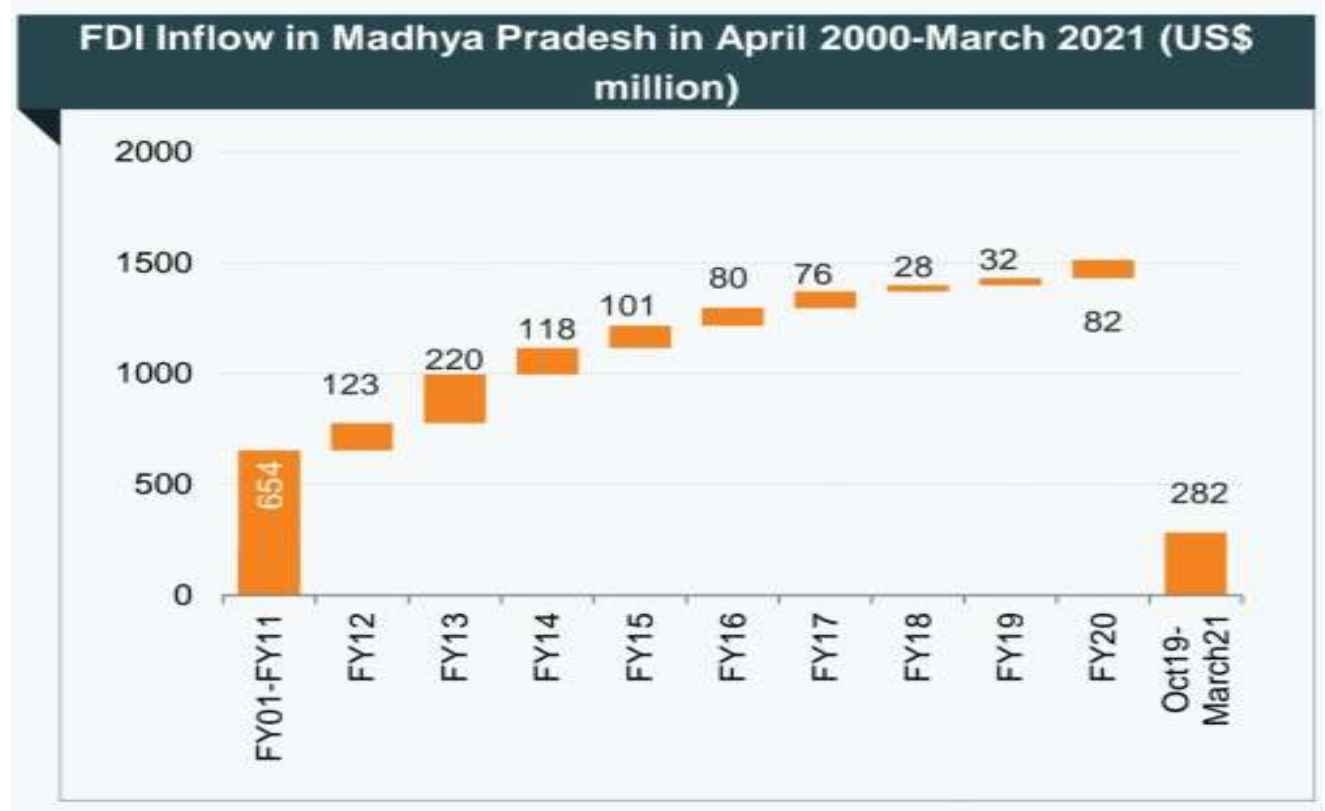

Investment intentions in terms of IEMs filed, LOIs / DILs issued

\begin{tabular}{|c|cc|}
\hline Year & Number & Proposed Investments (US\$ billion) \\
\hline 2017 & 76 & 1.10 \\
2018 & 140 & 3.49 \\
2019 & 178 & 2.47 \\
2020 & 93 & 4.42 \\
\hline
\end{tabular}




\section{Economic Outlook -Export trends:}

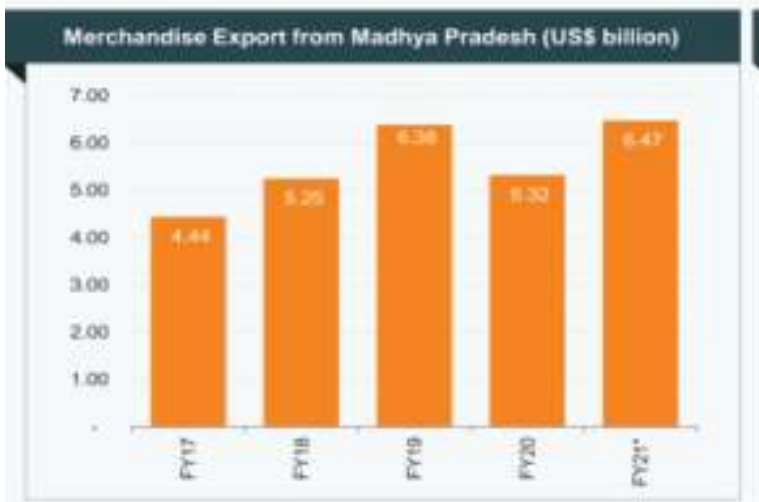

- Exports from the state stood at US5 8.47 bilion in FY21

\section{Physical infrastructure -Roads:}

1) Madhya Pradesh has national highways stretching to 8 , $940.54 \mathrm{kms}$ (FY21). The state also has 11, $389 \mathrm{~km}$ of state highways, as of September 2019. Under the State Budget 2021 - 22, the govt has allocated Rs.6, 957 crore (US\$ 948.60 million) for development of roads and bridges.

2) Rs.850 crore (US\$ 115.89 million) has been allocated for the repair and upgrade of roads and Rs.620 crore (US\$ 84.55 million) has been allocated for the construction of roads in rural areas.

Physical infrastructure -Power:
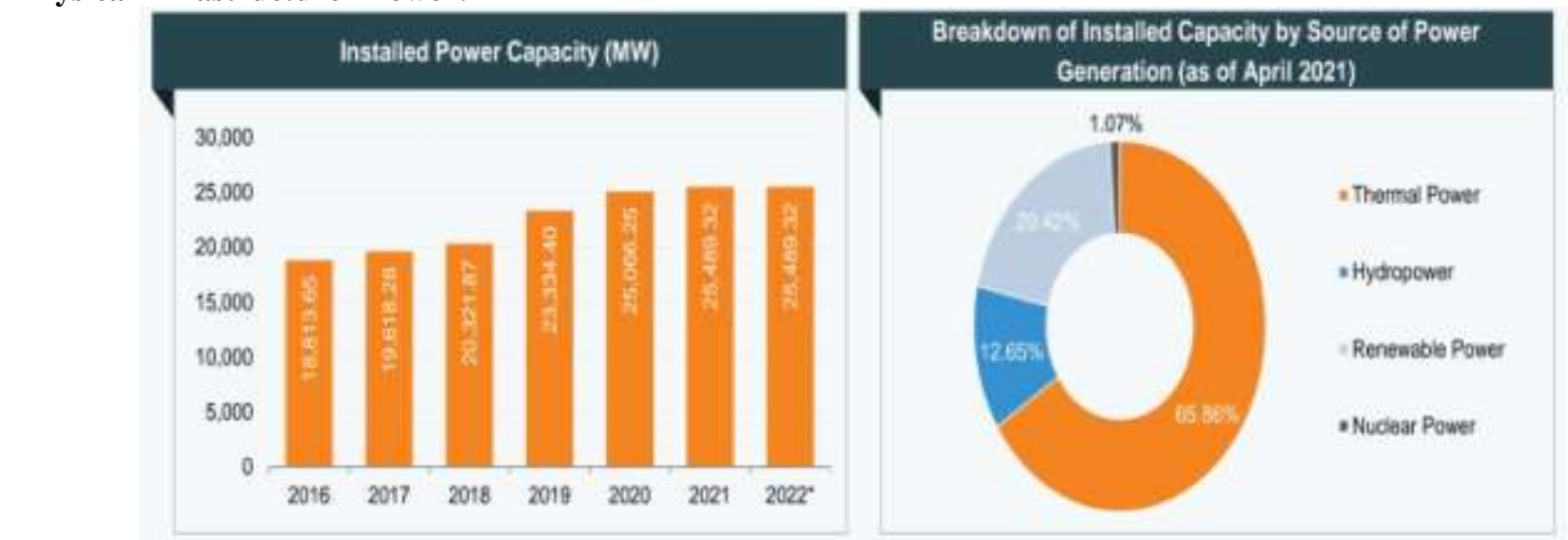

3) In August 2020, the Union Minister for Road Transport, Highways and MSMEs Mr. Nitin Gadkari laid the foundation stones for 45 highway projects in Madhya Pradesh. Rs.1.25 trillion (US\$ 16.95 billion) worth of development work is underway in Madhya Pradesh. 60 - 70\% work has been completed on road works approx. worth Rs.300 billion (US\$ 4.07 billion). These roads are aiming to improve connectivity to the tourist spots and backward areas of the state. The Minister announced that development work worth Rs.500 billion (US\$ 6.78 billion) is likely to be completed by 2023 .

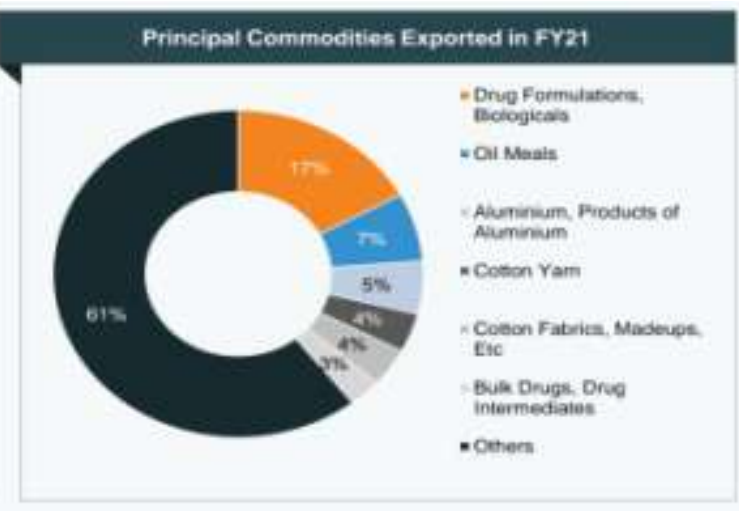

Key sectors - Agriculture and Food processing:

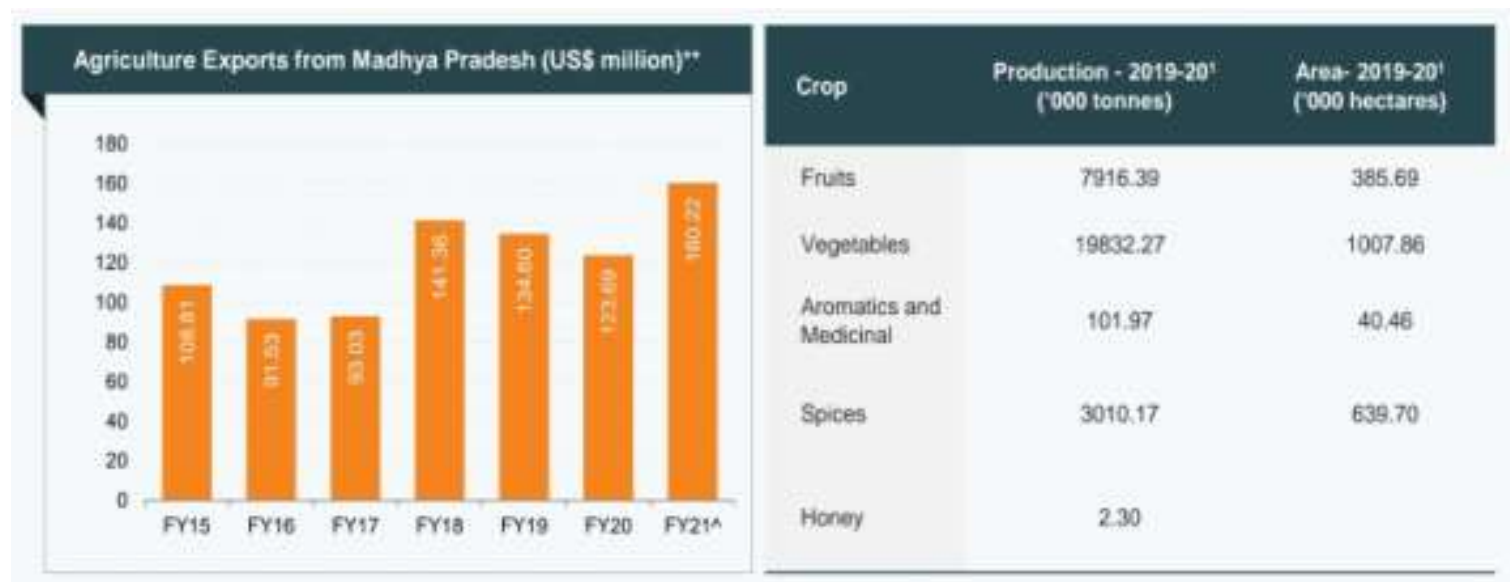

\begin{tabular}{|c|c|c|}
\hline Crop & $\begin{array}{l}\text { Production }-2019-20^{\prime} \\
\text { ('000 tonnes) }\end{array}$ & $\begin{array}{l}\text { Areat 2019-20') } \\
\text { (000 hectares) }\end{array}$ \\
\hline Fruns & 791639 & 385.69 \\
\hline Vogetabies & 19832.27 & 1007.86 \\
\hline $\begin{array}{l}\text { Aromatics and } \\
\text { Meoicinal }\end{array}$ & 101.97 & 40,46 \\
\hline Spices & 3010.17 & 639.70 \\
\hline Honey & 230 & \\
\hline
\end{tabular}




\section{Key sectors -Textiles:}

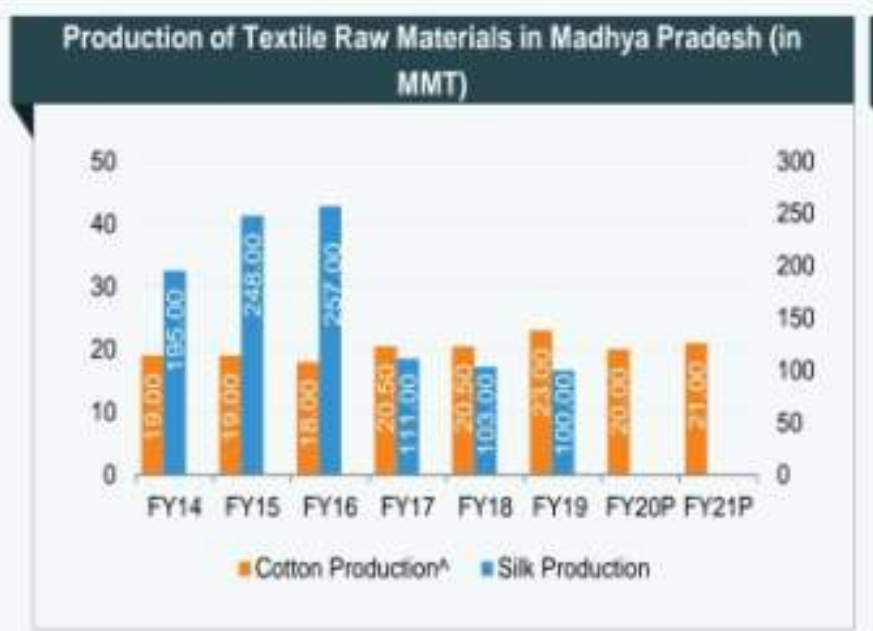

Key sectors -Tourism:

1) In 2019, foreign tourist arrivals and domestic tourist visits in the state stood at 0.33 million and 88.71 million, respectively.

2) As per State Budget 2019 - 20, the state Government proposed an allocation of Rs.229 crore (US\$ 32.77 million) for the development of the state's tourism department. Total tourist arrivals in Madhya Pradesh (in millions) 90.0089 .0088 .0087 .0086 .0085 .0084 .00 $\begin{array}{lllllllll}83.00 & 82.00 & 81.00 & 0.38 & 83.97 & 0.33 & 88.71 & 0.38 & 83.97\end{array}$ 2017.

3) In June 2021, Madhya Pradesh Tourism Board collaborated with Travelxp, a travel channel, to showcase the beauty and uniqueness of its tourism destinations to travelers worldwide.

\section{Total tourist arrivals in Madhya Pradesh (in millions)}

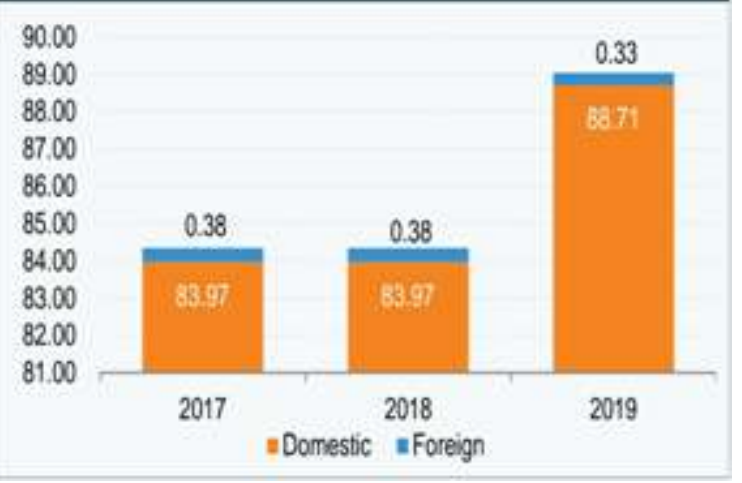

Key sectors -Pharmaceuticals:

1) Madhya Pradesh is home to over 280 pharmaceutical units operating in the industrial areas of Dewas, Indore, Pithampur, Mandideep and Malanpur.

2) Indore is one of the largest producers of pharmaceuticals like tablets, capsules, formulations in India.

3) Pithampur SEZ located in Indore is a production hub for pharmaceutical majors such as Cipla, Lupin, Mylan, etc.

4) Exports of drug formulations and biologicals accounted for $\sim 17 \%$ of the state's total exports in FY21.

\section{Exports of Cotton Yarn from Madhya Pradesh (USS million)}
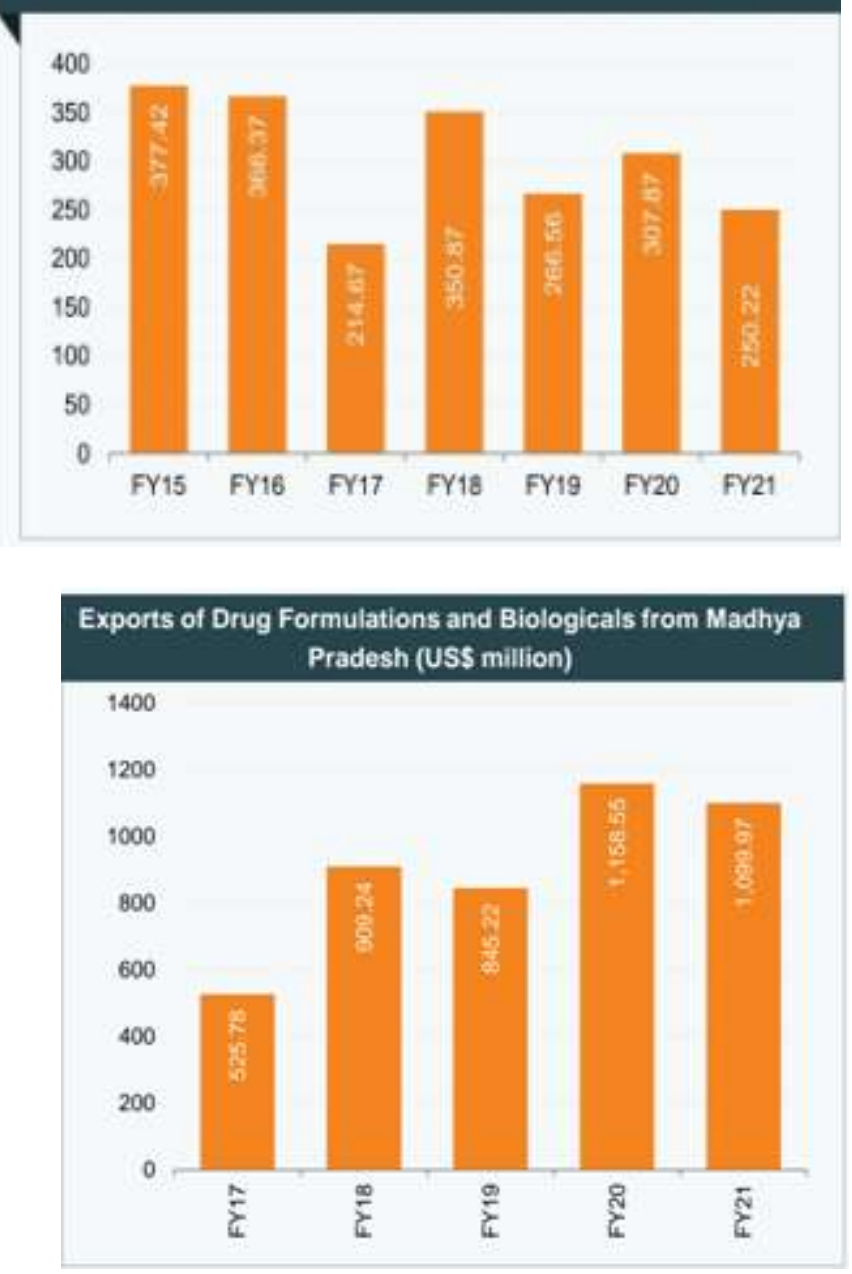

\section{Challenges Faced by Startups in India}

It is still early days for the Indian startup ecosystem and scaling challenges include:

1) A large market opportunity but Indians still do not have the discretionary income needed to create unparalleled products. India's middle class of about 78 million only earn INR 250, 000 per year according to the National Institute for Applied Economic Research (The Economist 2019) and only 50 million have shopped online (Google, Bain \& Company and Omidyar Network 2019).

2) Regulatory and taxation complexities also affect startup profitability. Corporate tax rates are high, although recently reduced to $22 \%$ and $14 \%$ in 2019 from $33 \%$. Terms for startups to qualify for government benefits are too stringent and the application process cumbersome, and once revenues exceed INR 1 billion they are disqualified. This has led to a third of the entrepreneurs actively looking at relocating out of India to reduce compliance and tax burdens, according to a survey (LocalCircles 2019).

3) Indian startups, like their global counterparts, struggle with a high failure rate with technology venture success rates at lower than 5\% worldwide. While incubators and 
accelerators have been most effective in supporting startups, the government will need to focus on simplifying regulation around registering companies, bankruptcy laws, and getting failed entrepreneurs back into the system.

4) Many Indian startups want to expand globally but face issues of credibility, except for software as a service (SaaS players) players, and even such entrepreneurs cannot tap into a global market as they are often unaware of global market opportunities.

5) India also struggles with a lack of innovation, lagging behind Japan, the PRC, and the Republic of Korea in international patents. One study cited lack of innovation as the most common reason for the high rate of failure (IBM Institute for Business Value and Oxford Economics 2016).

6) A lack of skilled workforce, inadequate formal mentoring, and poor business ethics with over $70 \%$ of India's engineering graduates being considered "unemployable." New emerging industries such as deep - tech and deep - science startups that are technology based are hampered by the lack of specialized talent (PhDs, researchers, etc.).

\section{Conclusion}

Empirically, we've visible in this study that the expanded competitiveness of states accounts for increased investments in startups inside the state. This indicates that once state make investments extra in $R \& D$, making it simpler to file patents, and develop tie - ups with universities and industry by means of expanding the incubator/accelerator ecosystem, startups benefit from better investment and access to technology and expertise. The government will now want to recognition on raising top - notch technical talent and international business skills through "reverse brain - drain" and making India a startup - friendly nation. India can learn from Israel and nations that make investments heavily in $\mathrm{R} \& \mathrm{D}$, and strengthen linkages between startups, corporates, academic institutions, and the government. India punches above its weight in terms of international innovation and much more can be accomplished in developing human capital and investing in higher education and putting in place an intellectual property approach in innovation. Startups in India will also require support for entrepreneurs and innovators who are frequently only interested and constrained in producing their own products and services and do not have the expertise and capacity scale with higher accounting, marketing, and sales.

\section{References}

[1] https://www.ibef.org/states/madhya-pradeshpresentation

[2] http://aiggpa.mp.gov.in/uploads/files/Start-up

[3] https://inc42.com/startups/madhya-pradesh-startupecosystem/amp

[4] https://www.indiafilings. com/learn/madhya-pradeshincubation-and-startup-policy

[5] https://www.startupindia.gov.in/srf/reports/Madhya_Pra desh_Report_26072020

[6] https://mpmsme.gov.in:8080/website/startup 